T. Q. DAVIES, M. J. TILBY, D. SKOLC, A. HALL, M. C. WILlis* (UNIVERSity OF OXFORD, UK)

Primary Sulfonamide Synthesis Using the Sulfinylamine Reagent $N$-Sulfinyl-O-(tert-butyl)hydroxylamine, $t$-BuONSO

Org. Lett. 2020, 22, 9495-9499, DOI: 10.1021/acs.orglett.0c03505.

\title{
Preparation of Primary Sulfonamides by $t$-BuONSO and Organometallics
}

\section{Category}

Metals in Synthesis

\section{Key words}

sulfonamides

Grignard reagents

organometallics

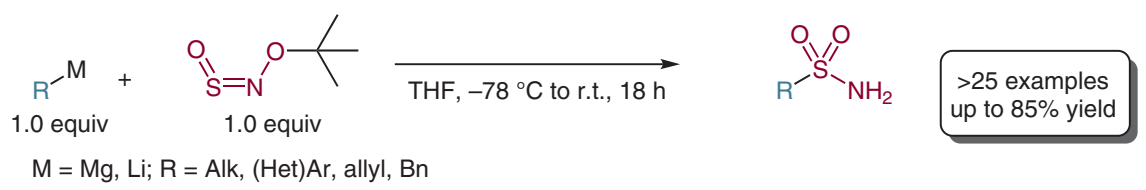

$M=M g, L i ; R=A l k,(H e t) A r$, allyl, Bn

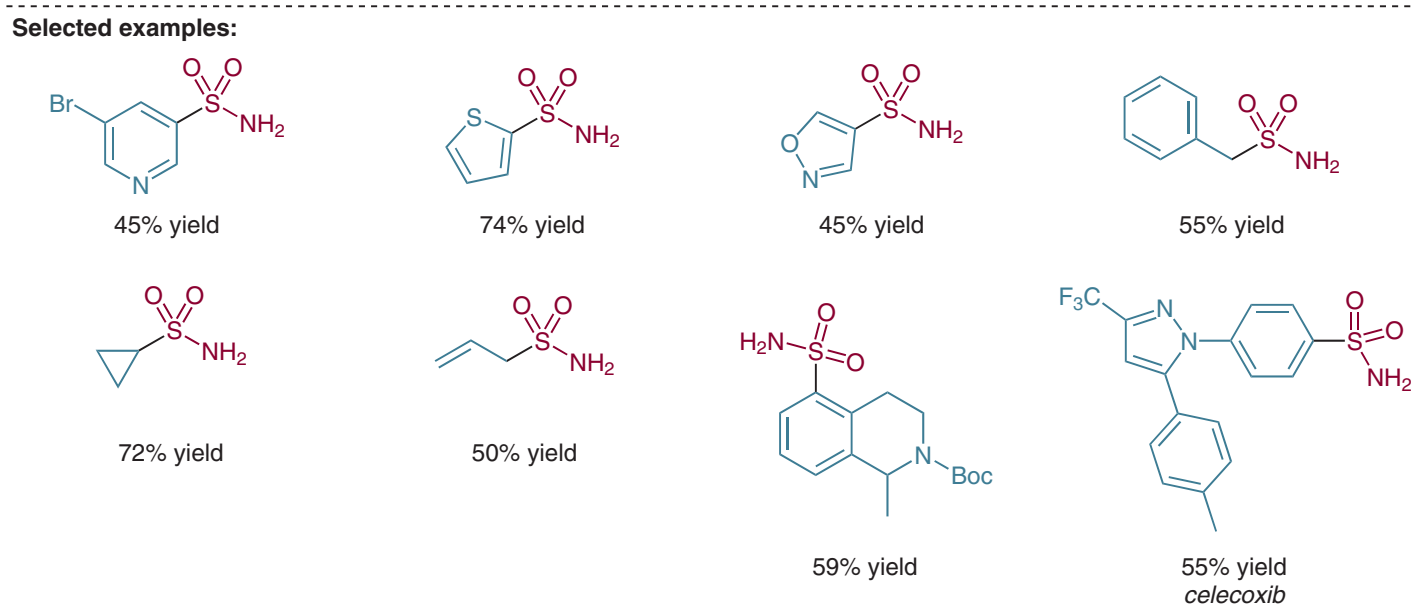

Proposed reaction mechanism:
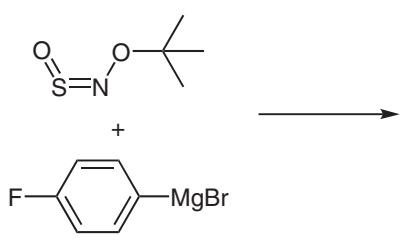<smiles>CC(C)(C)ONS(=O)c1ccc(F)cc1</smiles>

A<smiles>NS(=O)(=O)c1ccc(F)cc1</smiles>

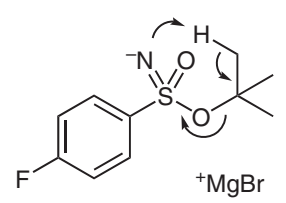

$B$<smiles>[3H][131I]C(=C)C</smiles><smiles>NS(=O)(=O)c1ccc(F)cc1</smiles>

C
Significance: Willis and co-workers report the reaction of readily available organometallic reagents and the novel sulfinylamine reagent $t$-BuONSO [N-sulfinyl-O-(tert-butyl)hydroxylamine] for the direct synthesis of primary sulfonamides in good yields.
Comment: The authors proposed a reaction mechanism in which, after nucleophilic attack of the Grignard reagent, the sulfinamide $A$ was formed. This intermediate was converted into B, either via a sulfinyl nitrene intermediate or by a concerted $\mathrm{N} \rightarrow \mathrm{S} \mathrm{O}$ migration. After an intermolecular proton transfer, isobutene was eliminated, giving the anion C, which was quenched after work-up to yield the desired sulfonamide. 